\title{
The Application of a Handheld Personal Digital Assistant with Camera and Mobile Phone Card (Wellnavi) to the General Population in a Dietary Survey
}

\author{
Shigeshi KIKUnAgA ${ }^{1}$, Tomoe TIN ${ }^{1}$, Genji IsHIBASHI ${ }^{2}$, Da-Hong WANG $^{3}$ and Shohei KIRA ${ }^{3}$ \\ ${ }^{1}$ Faculty of Sciences of Human Life, Notre Dame Seishin University, 2-16-9 Ifuku-cho, \\ Okayama 700-8516, Japan \\ ${ }^{2}$ Faculty of Home Economics, Kyushu Women's University, Yahatanishi-ku, Kitakyushu 807-8586, Japan \\ ${ }^{3}$ Department of Public Health, Okayama University Graduate School of Medicine and Dentistry, \\ 2-5-1 Shikata-cho, Okayama 700-8558, Japan
}

(Received June 1, 2006)

\begin{abstract}
Summary This study was carried out to examine first, the validity of a new dietary assessment method, a handheld personal digital assistant with camera and mobile phone card (Wellnavi), in comparison with a weighed diet record as a reference method and second, the relation between obesity and underreporting in the Wellnavi method in 27 men and 48 women volunteers aged 30-67 y from the general population. On the validity, there were significant correlations $(0.32-0.75)$ between the daily nutrient intakes measured by the Wellnavi method and the weighed diet record method in all the subjects except for some nutrients such as iron, magnesium and vitamin E. Results similar to those from the group of all the subjects were obtained in the men's group and the women's group. In all the subjects and the men's group and the women's group, the differences in the daily nutrient intakes between the two dietary assessment methods were statistically significant. However, good agreement of the differences between the two dietary assessment methods for many daily nutrient intakes was obtained in the nonobese men. The nutrient intakes estimated by the Wellnavi method in all the subjects and the men's group and the women's group were significantly lower than those values estimated by the weighed diet record method except for some nutrients such as sodium, iron and fat-soluble vitamins. With respect to the relation between obesity and underreporting, the obesity in women was not a factor of underreporting in the Wellnavi method, but the presence of this relation was undeniable in the obese men. The reason why the values of daily nutrient intakes in the Wellnavi method were lower than those estimated by the weighed diet record method seemed to be the low quality of the digital photo of the Wellnavi instrument. By improving the digital photo quality of this instrument, the Wellnavi method could become a useful new dietary assessment method to get accurate dietary information from people of a wide range of age and occupation, and a wide variety of physical situations of subjects from the general population.
\end{abstract}

Key Words dietary survey, mobile phone card, weighed diet record method, validity, general population

It has been clarified in several nutritional epidemiologic studies that there is a close relationship between daily nutrient intakes and lifestyle-related disorders (1). The dietary assessment method is indispensable in order to survey accurately daily nutrient intakes of a target population attending nutrition counseling. It is also for the sake of prevention of lifestyle-related disorders and for the development of research in nutrition science. The 24-h dietary recall, weighed diet record and food frequency questionnaires (FFQ) are widely used for the collection of dietary information on names of foods and amounts consumed by an individual (2). The accuracy of the daily nutrient intakes obtained from the 24-h dietary recall method is dependent on the ability of interviewer and the respondents' memory.

E-mail: kikunaga@post.ndsu.ac.jp
As the weighed diet record method provides comparatively accurate information on the quantity of the foods consumed during the investigation period, this record method is mainly used as an evaluation criterion for other dietary assessment methods such as FFQ (3). However, it costs a lot to carry out this record method, and the burden on the subjects is significant. Moreover, this record method does not provide information reflecting eating habits and can not be applied in large-scale nutritional epidemiological studies (2). Against this record method, the FFQ is comparatively inexpensive to carry out, the data processing is easy, application to large-scale nutritional epidemiologic studies is possible, and dietary information reflecting the eating habits of the subject is obtained. The FFQ is used frequently for dietary surveys (2). However, the FFQ does not supply precise information on diet intake. On the other hand, it 
Table 1. Physiological characteristics of the subjects.

\begin{tabular}{|c|c|c|c|c|c|c|}
\hline & & $n$ & $\begin{array}{l}\text { Age } \\
(y)\end{array}$ & $\begin{array}{l}\text { Height } \\
(\mathrm{cm})\end{array}$ & $\begin{array}{l}\text { Weight } \\
(\mathrm{kg})\end{array}$ & $\mathrm{BMI}^{\mathrm{a}}$ \\
\hline \multicolumn{2}{|c|}{ All subjects } & 75 & $48.8 \pm 10.2$ & $160 \pm 10.3$ & $62.2 \pm 9.98$ & $24.2 \pm 2.61$ \\
\hline \multicolumn{2}{|c|}{ All men } & 27 & $44.3 \pm 9.46$ & $170 \pm 9.25$ & $69.9 \pm 11.6$ & $24.2 \pm 2.95$ \\
\hline \multicolumn{2}{|c|}{ All women } & 48 & $51.4 \pm 9.88$ & $155 \pm 6.01$ & $57.9 \pm 5.45$ & $24.3 \pm 2.42$ \\
\hline \multirow[t]{2}{*}{ Men } & Nonobese & 17 & $42.1 \pm 8.23$ & $169 \pm 9.72$ & $64.3 \pm 9.91$ & $22.3 \pm 1.74$ \\
\hline & Obese & 10 & $48.2 \pm 10.6^{*}$ & $170 \pm 8.88$ & $79.4 \pm 7.49^{* *}$ & $27.4 \pm 1.28^{* *}$ \\
\hline \multirow[t]{2}{*}{ Women } & Nonobese & 26 & $50.6 \pm 9.70$ & $156 \pm 5.89$ & $55.1 \pm 4.40$ & $22.6 \pm 1.68$ \\
\hline & Obese & 22 & $52.3 \pm 10.2$ & $153 \pm 5.70$ & $61.3 \pm 4.58^{* *}$ & $26.3 \pm 1.41^{* *}$ \\
\hline \multirow[t]{2}{*}{$\mathrm{Men}^{\mathrm{b}}$} & Nonobese & 13 & $42.5 \pm 7.45$ & $171 \pm 10.5$ & $65.8 \pm 10.7$ & $22.4 \pm 1.89$ \\
\hline & Obese & 6 & $44.3 \pm 12.0$ & $172 \pm 10.8$ & $80.7 \pm 8.17$ & $27.4 \pm 1.34$ \\
\hline \multirow[t]{2}{*}{ Women $^{\mathrm{b}}$} & Nonobese & 10 & $47.5 \pm 9.08$ & $155 \pm 6.76$ & $54.3 \pm 4.99$ & $22.6 \pm 1.93$ \\
\hline & Obese & 8 & $52.8 \pm 10.5$ & $154 \pm 5.34$ & $62.3 \pm 4.85$ & $26.3 \pm 1.33$ \\
\hline
\end{tabular}

Each value is mean \pm SD.

${ }^{a}$ BMI: body mass index (body weight $\mathrm{kg} /(\text { body height } \mathrm{m})^{2}$ ).

${ }^{\mathrm{b}}$ The subjects participated in the motion and time study.

Significantly different from nonobese men or women: ${ }^{* *} p<0.01,{ }^{*} p<0.05$.

was reported that misreporting of daily food intakes in both the 24-h recall and weighed diet record methods has been observed in both men and women and among subjects of a wide range of age (4-6). It is known that obesity is a factor in the underreporting of usual food intake (4, 7-12). For dietary assessment methods used at present, it has been indicated that there is a problem in the accuracy of daily food intake reported by the subject. The development of a new dietary assessment method which evaluates accurately daily nutrient intakes of the subject is desired (13).

Using college women who majored in food and nutrition as subjects, Wang et al. compared the daily nutrient intakes estimated by the Wellnavi method with those from the weighed diet record method, and reported that the validity and reliability of the Wellnavi method for dietary assessment were extremely high. The Wellnavi method is a useful method to measure individual dietary intakes for a variety of nutrients in an epidemiologic study (14). Using the Wellnavi instrument, the subjects take digital photos of foods and drink before and after their meal, and send these digital photos to the dietician electronically for estimation of the daily nutrient intakes. Then the list of daily nutrient intakes estimated from the digital photos by the dietician is electronically transmitted to the subject (14). The purpose of this study was to examine the validity of the daily nutrient intakes obtained from the Wellnavi method in the subjects from a general population in comparison with those estimated by the weighed diet record method. In addition, whether obesity became a factor of underreporting of usual food intake estimated by the Wellnavi method was examined by comparing it with the daily energy intake estimated from the weighed diet record method and the daily energy expenditure calculated from a motion and time study.

\section{SUBJECTS AND METHODS}

Subjects. For the subjects of this study, we recruited male and female volunteers aged 30 to $70 \mathrm{y}$ though an advertisement sponsored by the Foundation of Yakagecho Health Administration Center. The subjects who participated in this study were 75 healthy adult volunteers (27 men and 48 women aged 30-67y) from Yakage-cho in Okayama Prefecture, Japan. They were 17 nonobese men and 10 obese men, and 26 nonobese women and 22 obese women. The physiological characteristics of the subjects are shown in Table 1. The height and body weight of the subjects were measured just before beginning this study. The subjects were, on average, $48.8 \mathrm{y}$ of age, $160 \mathrm{~cm}$ in height, $62.2 \mathrm{~kg}$ in weight and 24.2 in BMI. The men subjects were, on average, $44.3 \mathrm{y}$ of age, $170 \mathrm{~cm}$ in height, $69.9 \mathrm{~kg}$ in weight and 24.2 in BMI. The women subjects were, on average, $51.4 \mathrm{y}$ of age, $155 \mathrm{~cm}$ in height, $57.9 \mathrm{~kg}$ in weight and 24.3 in BMI. The body weight and BMI of the obese of men and women were significantly higher than those in the nonobese of men and women. When conducting this study, we supplied both oral and written information to the subjects about the nature and purpose of this study, and allowed them to leave this study if they wished and to keep personal information obtained through the survey. A signed informed consent was obtained from the all subjects participating in this study. The ethical committee of Okayama University approved the protocol of this study.

Dietary assessment. Dietary assessment was conducted in all the subjects using both the Wellnavi instrument (Matsushita Electric Works, Ltd, Japan) and the weighed diet record method during 5 consecutive day periods from the end of January to early February 2002. These two dietary assessment methods were applied to the same meal of the subjects during the 
same period as the dietary survey. The Wellnavi instrument consisted of three parts: a camera which produces a photo of the meal; a display on which to write the names of the ingredients of the dishes in the digital photo of the meal using a stylus (an attachment of the instrument) or to show the nutrient intakes of the subject calculated by the dietician; and a mobile phone card attachment which transmits the digital photo and receives the calculated nutrient intakes electronically. It was reported that the quality of the information on daily nutrient intakes estimated by Wellnavi depends on the angle position of this instrument while taking a digital photo of the meal, and the correct use of this instrument was described amply in a previous report (14). It was confirmed that the subjects could use this instrument adequately before starting the dietary survey. The weighed diet record method was carried out to estimate the daily nutrient intakes of the subjects once they understood the measuring method of gram weight of foods, beverages and seasonings such as salt and soy sauce, and had practiced filling out the record paper. The daily nutrient intake of the subjects was calculated by the use of nutritional value calculation software (health make win. ver. 2.1, Health Make System Laboratory, Yokohama) produced on the basis of the fifth edition of Standard Tables of Food Composition in Japan (15). To calculate the daily nutrient intake of the subjects, the intake of each nutrient obtained for $5 \mathrm{~d}$ was averaged.

Validity study. To evaluate the validity of the Wellnavi instrument, the daily nutrient intakes of the subjects obtained from this instrument were compared with those of the weighed diet record as a reference method. The correlation and significance between the daily nutrient intakes estimated from these two dietary assessment methods were examined.

Relation between obesity and underreporting in the Wellnavi instrument. The subjects were divided into a non-obesity group of under BMI 25 and an obesity group of over BMI 25 (16). The relation between the obesity and underreporting in the Wellnavi instrument was examined in comparison with the daily nutrient intakes estimated by the weighed diet record method between the nonobese men and obese men, and nonobese women and obese women. In addition, the daily energy intake estimated by the weighed diet record method was compared with 1-d energy expenditure obtained from a motion and time study between the nonobese men and obese men, and nonobese women and obese women. For this purpose, some subjects who volunteered to estimate energy expenditure were asked to complete a 5-min-interval activity diary for $3 \mathrm{~d}$. Oneday energy expenditure was calculated by the motion and time study for the 19 men (13 nonobese and 6 obese) and 18 women (10 nonobese and 8 obese) who completed a 5-min-interval activity diary for the last $3 \mathrm{~d}$ during the same period as the dietary survey. Their 24-h energy expenditure was compared with the daily energy intake obtained by the weight diet record method conducted during the same period.
The motion and time study. It is known that energy expenditure and energy intake are equal under conditions of stable body weight and composition (17). To confirm the accuracy of the weight diet record method in comparison with the motion and time study instead of the doubly labeled water technique as a criterion method (18), the motion and time study was carried out to calculate 1-d energy expenditure of the subjects, and then the results from the motion and time study were compared with the daily energy intake obtained from the weight diet record method. The subjects who participated in the estimation of total energy expenditure kept an activity diary over the last $3 \mathrm{~d}$ during survey period when the dietary survey was conducted by the use of the Wellnavi instrument and by application of the weighed diet record method. The activity diary questionnaire consisted of the tables of time with the blanks to fill in the nature and the time of the each activity. The table of time divided 24-h into 5-min intervals. Participants were instructed how to record the nature of each activity in the activity diary questionnaire, using a completed sample as a model. This model and the classification table of activities were given to the subjects to facilitate keeping the activity diary. They drew a line at the end of one activity under the corresponding indicator of time and filled the number of each activity chosen from the classification table into the blanks. Then, the activity diary questionnaires were collected and checked for omission of recording. The data from the activity diary were converted into energy expenditure by software (health make win. ver. 2.1, Health Make System Laboratory) produced on the basis of the activity factor (19). One-day energy expenditure of the subjects was calculated by averaging the values obtained for $3 \mathrm{~d}$.

Statistic analysis. Values in the tables are shown as mean \pm SD. All analyses were performed by the use of a computer program (Excel ver. 5.0). The correlation coefficient between the nutrient intakes obtained from the Wellnavi method and the weighed diet record method was calculated by Spearman rank correlation. The significant difference and significant correlation coefficient of the results obtained from the Wellnavi method and the weighed diet record method, and the significant difference between the weighed diet record method and the motion and time study were assessed using the paired $t$ test.

\section{RESULTS}

\section{Comparison of two dietary assessment methods}

The difference and the correlation coefficient of the estimated daily nutrient intakes in all the subjects between two dietary assessment methods are shown in Table 2. The Wellnavi method gave significantly lower values for the daily nutrient intakes in all the subjects than those obtained by the weighed diet record method, except for sodium, iron, retinol equivalents, vitamins D, $\mathrm{E}, \mathrm{K}$ and $\mathrm{B}_{12}$, cholesterol and salt. There were significant correlation coefficients between the daily nutrient intakes estimated by the Wellnavi method and the 
Table 2. The difference and the correlation coefficient in estimated daily nutrient intake in all subjects between the two dietary assessment methods.

\begin{tabular}{|c|c|c|c|c|}
\hline & $\begin{array}{l}\text { Wellnavi } \\
\mathrm{M} \pm \mathrm{SD}\end{array}$ & $\begin{array}{l}\text { Weighed diet record } \\
\qquad \mathrm{M} \pm \mathrm{SD}\end{array}$ & Difference $^{a}$ & $\begin{array}{l}\text { Correlation } \\
\text { coefficient }^{\mathrm{a}}\end{array}$ \\
\hline Energy (kcal) & $1,718 \pm 361$ & $1,977 \pm 405$ & $* * *$ & $0.602^{* * *}$ \\
\hline Protein $(\mathrm{g})$ & $66.7 \pm 14.2$ & $77.0 \pm 15.7$ & $* * *$ & $0.557^{* * *}$ \\
\hline Fat $(\mathrm{g})$ & $48.1 \pm 12.9$ & $53.1 \pm 15.1$ & $*$ & $0.692^{* * *}$ \\
\hline Carbohydrates (g) & $239 \pm 52.9$ & $273 \pm 55.0$ & $* * *$ & $0.564^{* * *}$ \\
\hline Sodium (mg) & $3,738 \pm 822$ & $3,596 \pm 939$ & NS & $0.331^{* *}$ \\
\hline Potassium (mg) & $2,418 \pm 538$ & $3,064 \pm 966$ & $* * *$ & $0.368^{* *}$ \\
\hline Calcium (mg) & $463 \pm 141$ & $573 \pm 171$ & $* * *$ & $0.411^{* *}$ \\
\hline Magnesium (mg) & $249 \pm 52.3$ & $307 \pm 74.8$ & $* * *$ & $0.340^{* *}$ \\
\hline Phosphorus (mg) & $960 \pm 204$ & $1,139 \pm 232$ & $* * *$ & $0.514^{* * *}$ \\
\hline Iron (mg) & $8.40 \pm 4.00$ & $9.21 \pm 2.43$ & NS & 0.081 \\
\hline Zinc (mg) & $8.50 \pm 2.06$ & $9.66 \pm 2.17$ & $* *$ & $0.581^{* * *}$ \\
\hline Copper (mg) & $1.17 \pm 0.320$ & $1.43 \pm 0.495$ & $* * *$ & $0.597^{* * *}$ \\
\hline Manganese (mg) & $2.79 \pm 0.599$ & $6.19 \pm 7.51$ & $* * *$ & 0.208 \\
\hline Retinol equivalents $(\mu \mathrm{g})$ & $1,040 \pm 384$ & $1,096 \pm 447$ & NS & $0.390^{* *}$ \\
\hline Vitamin $\mathrm{D}(\mu \mathrm{g})$ & $8.24 \pm 5.76$ & $9.63 \pm 5.85$ & NS & $0.776^{* * *}$ \\
\hline Vitamin E (mg) & $8.58 \pm 7.12$ & $8.47 \pm 1.99$ & NS & 0.095 \\
\hline Vitamin $\mathrm{K}(\mu \mathrm{g})$ & $312 \pm 163$ & $320 \pm 199$ & NS & $0.415^{* * *}$ \\
\hline Vitamin $B_{1}(\mathrm{mg})$ & $0.790 \pm 0.198$ & $1.01 \pm 0.238$ & $* * *$ & $0.467^{* * *}$ \\
\hline Vitamin $\mathrm{B}_{2}(\mathrm{mg})$ & $1.06 \pm 0.263$ & $1.39 \pm 0.349$ & $* * *$ & $0.545^{* * *}$ \\
\hline Niacin (mg) & $14.1 \pm 3.89$ & $18.8 \pm 5.81$ & $* * *$ & $0.461^{* * *}$ \\
\hline Vitamin $\mathrm{B}_{6}(\mathrm{mg})$ & $1.18 \pm 0.288$ & $1.44 \pm 0.374$ & $* * *$ & $0.571^{* * *}$ \\
\hline Vitamin $\mathrm{B}_{12}(\mu \mathrm{g})$ & $8.14 \pm 4.81$ & $9.40 \pm 6.18$ & NS & $0.770^{* * *}$ \\
\hline Folacin $(\mu \mathrm{g})$ & $349 \pm 86.8$ & $474 \pm 281$ & $* * *$ & $0.304^{*}$ \\
\hline Pantothenic acid (mg) & $5.43 \pm 1.27$ & $6.47 \pm 1.33$ & $* * *$ & $0.617^{* * *}$ \\
\hline Vitamin C (mg) & $98.4 \pm 30.8$ & $133 \pm 64.4$ & $* * *$ & $0.470^{* * *}$ \\
\hline Cholesterol (mg) & $333 \pm 132$ & $375 \pm 153$ & NS & $0.752^{* * *}$ \\
\hline Dietary fiber, total (g) & $13.5 \pm 3.17$ & $16.2 \pm 6.06$ & $* * *$ & $0.353^{* *}$ \\
\hline Salt $(\mathrm{g})$ & $9.43 \pm 2.07$ & $9.07 \pm 2.37$ & NS & $0.325^{*}$ \\
\hline
\end{tabular}

Each value is mean \pm SD.

${ }^{a}$ The difference and a correlation coefficient mean a significant difference between the Wellnavi and the weighed diet record methods.

${ }^{* * *} p<0.001,{ }^{* *} p<0.01,{ }^{*} p<0.05$.

weighed diet record method, except for iron, manganese and vitamin D. The correlation coefficients between the daily nutrient intakes estimated from these two dietary assessment methods were from 0.304 for folacin to 0.776 for vitamin $\mathrm{D}$.

The difference and the correlation coefficient of the estimated daily nutrient intakes in the men and women between the two dietary assessment methods are shown in Table 3. The differences and the correlation coefficients between the two dietary assessment methods are similar to those in all the subjects obtained in both men and women (Table 2).

Relationship between obesity and underreporting in the Wellnavi method

The difference and the correlation coefficient of the estimated daily nutrient intakes in nonobese and obese men between the two dietary assessment methods are shown in Table 4. There were significant correlation coefficients in many daily nutrient intakes in the nonobese men between the two dietary assessment methods, but not in obese men. No significant differences in most daily nutrient intakes estimated between the two dietary assessment methods were observed in the non- obese and obese men. On the other hand, the significant correlation coefficient between the two dietary assessment methods for many daily nutrient intakes was obtained in the nonobese men, but not in the obese men.

The difference and the correlation coefficient of the estimated daily nutrient intakes in the nonobese and obese women between the two dietary assessment methods are shown in Table 5. Between the two dietary assessment methods, approximately similar results for the difference and the correlation coefficient in the estimated daily nutrient intakes of the nonobese and obese women to those in all the subjects (Table 2) were obtained.

Relationship between the daily energy intake and the daily energy expenditure

The comparison of the daily energy intake from the weighed diet record method with the daily energy expenditure from the motion and time study in the nonobese and obese of men or women is shown in Table 6 . No significant differences between the daily energy intake from the diet record method and the daily energy expenditure from the motion and time study were observed in either nonobese or obese men or women. 
Table 3. The difference and the correlation coefficient in estimated daily nutrient intake in men and women between the two dietary assessment methods.

\begin{tabular}{|c|c|c|c|c|c|c|c|c|}
\hline & \multicolumn{4}{|c|}{ Men $(n=27)$} & \multicolumn{4}{|c|}{ Women $(n=48)$} \\
\hline & $\begin{array}{l}\text { Wellnavi } \\
\mathrm{M} \pm \mathrm{SD}\end{array}$ & $\begin{array}{l}\text { Weighed diet } \\
\text { record } \\
\mathrm{M} \pm \mathrm{SD}\end{array}$ & Difference $^{\mathrm{a}}$ & $\begin{array}{l}\text { Correlation } \\
\text { coefficient }^{\mathrm{a}}\end{array}$ & $\begin{array}{l}\text { Wellnavi } \\
\mathrm{M} \pm \mathrm{SD}\end{array}$ & $\begin{array}{l}\text { Weighed diet } \\
\text { record } \\
\mathrm{M} \pm \mathrm{SD}\end{array}$ & Difference $^{\mathrm{a}}$ & $\begin{array}{l}\text { Correlation } \\
\text { coefficient }^{\mathrm{a}}\end{array}$ \\
\hline E (kcal) & $1,873 \pm 334$ & $2,232 \pm 424$ & $* *$ & $0.615^{* * *}$ & $1,631 \pm 349$ & $1,833 \pm 317$ & $* *$ & $0.496^{* * *}$ \\
\hline$P(g)$ & $68.8 \pm 12.4$ & $79.2 \pm 12.9$ & $* *$ & $0.658^{* * *}$ & $65.5 \pm 15.2$ & $75.8 \pm 17.1$ & $* *$ & $0.517^{* * *}$ \\
\hline $\mathrm{F}(\mathrm{g})$ & $52.4 \pm 11.6$ & $59.7 \pm 13.9$ & $*$ & $0.773^{* * *}$ & $45.6 \pm 13.1$ & $49.4 \pm 14.7$ & NS & $0.617^{* * *}$ \\
\hline $\mathrm{C}(\mathrm{g})$ & $254 \pm 52.2$ & $289 \pm 60.5$ & $*$ & $0.708^{* * *}$ & $231 \pm 51.9$ & $264 \pm 50.1$ & $* *$ & $0.435^{* *}$ \\
\hline $\mathrm{Na}(\mathrm{mg})$ & $3,875 \pm 737$ & $3,749 \pm 964$ & NS & $0.414^{*}$ & $3,662 \pm 864$ & $3,510 \pm 924$ & NS & 0.277 \\
\hline $\mathrm{K}(\mathrm{mg})$ & $2,465 \pm 455$ & $2,694 \pm 422$ & NS & $0.581^{* *}$ & $2,393 \pm 583$ & $3,272 \pm 1117$ & $* * *$ & $0.391^{* *}$ \\
\hline $\mathrm{Ca}(\mathrm{mg})$ & $471 \pm 143$ & $558 \pm 175$ & NS & $0.645^{* * *}$ & $459 \pm 140$ & $581 \pm 170$ & $* * *$ & 0.281 \\
\hline $\mathrm{Mg}(\mathrm{mg})$ & $254 \pm 44.9$ & $287 \pm 46.5$ & $*$ & $0.609^{* * *}$ & $246 \pm 56.2$ & $318 \pm 85.3$ & $* * *$ & $0.310^{*}$ \\
\hline $\mathrm{P}(\mathrm{mg})$ & $994 \pm 181$ & $1,150 \pm 203$ & $* *$ & $0.656^{* * *}$ & $941 \pm 215$ & $1,132 \pm 249$ & $* * *$ & $0.461^{* *}$ \\
\hline $\mathrm{Fe}(\mathrm{mg})$ & $8.07 \pm 1.86$ & $8.49 \pm 1.58$ & NS & $0.513^{* *}$ & $8.59 \pm 4.81$ & $9.62 \pm 2.73$ & NS & 0.014 \\
\hline Zn (mg) & $9.17 \pm 1.94$ & $10.2 \pm 2.11$ & NS & $0.544^{* *}$ & $8.12 \pm 2.06$ & $9.38 \pm 2.18$ & $* *$ & $0.574^{* * *}$ \\
\hline $\mathrm{Cu}(\mathrm{mg})$ & $1.21 \pm 0.236$ & $1.40 \pm 0.270$ & $* *$ & 0.319 & $1.14 \pm 0.359$ & $1.45 \pm 0.587$ & $* *$ & $0.659^{* * *}$ \\
\hline Mn (mg) & $2.87 \pm 0.550$ & $3.49 \pm 0.872$ & $* *$ & $0.537^{* *}$ & $2.75 \pm 0.626$ & $7.70 \pm 9.04$ & $* * *$ & 0.267 \\
\hline V.A $(\mu \mathrm{g})$ & $1,088 \pm 356$ & $993 \pm 404$ & NS & 0.182 & $1013 \pm 400$ & $1,155 \pm 463$ & NS & $0.515^{* * *}$ \\
\hline V.D $(\mu \mathrm{g})$ & $6.68 \pm 4.00$ & $8.22 \pm 3.58$ & NS & $0.584^{* *}$ & $9.12 \pm 6.42$ & $10.4 \pm 6.71$ & NS & $0.802^{* * *}$ \\
\hline V.E (mg) & $10.1 \pm 11.4$ & $8.49 \pm 1.44$ & NS & -0.100 & $7.71 \pm 2.43$ & $8.46 \pm 2.25$ & NS & $0.551^{* * *}$ \\
\hline V.K $(\mu \mathrm{g})$ & $334 \pm 163$ & $271 \pm 118$ & NS & $0.607^{* * *}$ & $300 \pm 163$ & $347 \pm 229$ & NS & $0.418^{* *}$ \\
\hline V.B $B_{1}(\mathrm{mg})$ & $0.831 \pm 0.196$ & $1.05 \pm 0.245$ & $* * *$ & $0.470^{*}$ & $0.766 \pm 0.197$ & $0.986 \pm 0.233$ & $* * *$ & $0.448^{* *}$ \\
\hline V.B ${ }_{2}(\mathrm{mg})$ & $1.10 \pm 0.206$ & $1.35 \pm 0.279$ & $* * *$ & $0.767^{* * *}$ & $1.05 \pm 0.291$ & $1.42 \pm 0.383$ & $* * *$ & $0.502^{* * *}$ \\
\hline Niacin (mg) & $14.7 \pm 4.10$ & $18.9 \pm 4.90$ & $* *$ & $0.601^{* * *}$ & $13.7 \pm 3.77$ & $18.7 \pm 6.31$ & $* * *$ & $0.406^{* *}$ \\
\hline $\mathrm{V} \mathrm{B}_{6}(\mathrm{mg})$ & $1.25 \pm 0.282$ & $1.45 \pm 0.355$ & $*$ & $0.494^{* *}$ & $1.14 \pm 0.287$ & $1.43 \pm 0.388$ & $* * *$ & $0.615^{* * *}$ \\
\hline V.B $\mathrm{B}_{12}(\mu \mathrm{g})$ & $7.49 \pm 3.61$ & $9.18 \pm 5.26$ & NS & $0.705^{* * *}$ & $8.50 \pm 5.37$ & $9.52 \pm 6.69$ & NS & $0.793^{* * *}$ \\
\hline $\mathrm{Fa}(\mu \mathrm{g})$ & $359 \pm 74.4$ & $342 \pm 62.7$ & NS & $0.598^{* * *}$ & $344 \pm 93.3$ & $549 \pm 326$ & $* * *$ & $0.371^{*}$ \\
\hline $\mathrm{Pa}(\mathrm{mg})$ & $5.65 \pm 1.09$ & $6.44 \pm 1.26$ & $*$ & $0.734^{* * *}$ & $5.31 \pm 1.36$ & $6.49 \pm 1.37$ & $* * *$ & $0.583^{* * *}$ \\
\hline V.C (mg) & $100 \pm 24.8$ & $109 \pm 52.6$ & NS & $0.726^{* * *}$ & $97.5 \pm 33.9$ & $147 \pm 66.8$ & $* * *$ & $0.432^{* *}$ \\
\hline Cho (mg) & $337 \pm 111$ & $392 \pm 142$ & NS & $0.833^{* * *}$ & $331 \pm 143$ & $366 \pm 160$ & NS & $0.723^{* * *}$ \\
\hline $\mathrm{Df}(\mathrm{g})$ & $13.6 \pm 2.84$ & $13.6 \pm 2.36$ & NS & $0.717^{* * *}$ & $13.5 \pm 3.37$ & $17.6 \pm 7.00$ & $* * *$ & $0.346^{*}$ \\
\hline Salt (g) & $9.77 \pm 1.86$ & $9.44 \pm 2.45$ & NS & $0.408^{*}$ & $9.24 \pm 2.18$ & $8.86 \pm 2.33$ & NS & 0.271 \\
\hline
\end{tabular}

Each value is mean \pm SD.

E: energy, P: protein, F: fat, C: carbohydrate, Fa: folacin, Pa: pantothenic acid, Cho: cholesterol, Df: dietary fiber.

${ }^{a}$ The difference and a correlation coefficient mean a significant difference between the Wellnavi and the weighed diet record methods.

${ }^{* * *} p<0.001,{ }^{* *} p<0.01,{ }^{*} p<0.05$.

There was also no significant difference in the values of daily energy intake and daily energy expenditure between nonobese and obese men or women.

\section{DISCUSSION}

The present study evaluated the validity of a handheld personal digital assistant with a camera and mobile phone card, Wellnavi, in order to assess the dietary intake of individuals from a general population. For this purpose, the result obtained from the Wellnavi method was compared with that from the weight diet record as a reference method. In addition, the association between obesity and underreporting in the Wellnavi method was examined in comparison with the results from both the weighed diet record method, and the motion and time study. In this study, it was clear that the Wellnavi instrument is a useful new dietary assessment method to get accurate dietary information on the subjects from a general population. Further, obe- sity in women was not a factor in underreporting in the Wellnavi method, but the presence of this relation was undeniable in the obese men.

All the dietary assessment methods used to assess self-reported daily dietary intake have had several problems in terms of the accuracy of the measurement result (20-22). The accuracy of dietary assessment methods for estimating daily dietary intakes in a target population is gathering large interest from dietitians, nutritional research scientists and other health professionals. The validity and reliability of the Wellnavi method were confirmed in the previous study with college students majoring in food and nutrition. This method can provide good measurement results of usual dietary intakes (14). The system of the dietary assessment and intervention approach to subjects by the Wellnavi instrument has been described sufficiently in a previous report (14).

Significant correlation coefficients between the many 
Table 4. The difference and the correlation coefficient in estimated daily nutrient intake in nonobese and obese men between the two dietary assessment methods.

\begin{tabular}{|c|c|c|c|c|c|c|c|c|}
\hline & \multicolumn{4}{|c|}{ Nonobese men $(n=17)$} & \multicolumn{4}{|c|}{ Obese men $(n=10)$} \\
\hline & $\begin{array}{l}\text { Wellnavi } \\
\mathrm{M} \pm \mathrm{SD}\end{array}$ & $\begin{array}{l}\text { Weighed diet } \\
\text { record } \\
\mathrm{M} \pm \mathrm{SD}\end{array}$ & Difference $^{\mathrm{a}}$ & $\begin{array}{l}\text { Correlation } \\
\text { coefficient }^{\mathrm{a}}\end{array}$ & $\begin{array}{l}\text { Wellnavi } \\
\mathrm{M} \pm \mathrm{SD}\end{array}$ & $\begin{array}{l}\text { Weighed diet } \\
\text { record } \\
\mathrm{M} \pm \mathrm{SD}\end{array}$ & Difference $^{\mathrm{a}}$ & $\begin{array}{l}\text { Correlation } \\
\text { coefficient }^{\mathrm{a}}\end{array}$ \\
\hline $\mathrm{E}$ (kcal) & $1,932 \pm 373$ & $2,205 \pm 440$ & NS & $0.749^{* * *}$ & $1,772 \pm 239$ & $2,277 \pm 414$ & $* *$ & 0.416 \\
\hline $\mathrm{P}(\mathrm{g})$ & $69.4 \pm 12.7$ & $78.2 \pm 14.5$ & NS & $0.788^{* * *}$ & $67.7 \pm 12.4$ & $81.0 \pm 10.0$ & $*$ & 0.389 \\
\hline $\mathrm{F}(\mathrm{g})$ & $53.0 \pm 13.9$ & $59.1 \pm 15.3$ & NS & $0.851^{* * *}$ & $51.4 \pm 6.62$ & $60.6 \pm 11.6$ & NS & 0.494 \\
\hline $\mathrm{C}(\mathrm{g})$ & $267 \pm 55.5$ & $301 \pm 62.1$ & NS & $0.707^{* *}$ & $231 \pm 38.4$ & $267 \pm 54.0$ & NS & 0.614 \\
\hline $\mathrm{Na}(\mathrm{mg})$ & $3,824 \pm 749$ & $3,520 \pm 772$ & NS & 0.247 & $3,962 \pm 747$ & $4,140 \pm 1164$ & NS & 0.616 \\
\hline $\mathrm{K}(\mathrm{mg})$ & $2,501 \pm 474$ & $2,711 \pm 436$ & NS & $0.694^{* *}$ & $2,402 \pm 437$ & $2,666 \pm 418$ & NS & 0.351 \\
\hline Ca (mg) & $479 \pm 157$ & $555 \pm 181$ & NS & $0.811^{* * *}$ & $456 \pm 123$ & $563 \pm 175$ & NS & 0.278 \\
\hline $\mathrm{Mg}(\mathrm{mg})$ & $262 \pm 41.8$ & $293 \pm 46.6$ & NS & $0.681^{* *}$ & $241 \pm 48.9$ & $277 \pm 47.0$ & NS & 0.466 \\
\hline $\mathrm{P}(\mathrm{mg})$ & $1,016 \pm 186$ & $1,147 \pm 199$ & NS & $0.796^{* * *}$ & $956 \pm 176$ & $1,156 \pm 221$ & $*$ & 0.459 \\
\hline $\mathrm{Fe}(\mathrm{mg})$ & $7.89 \pm 1.55$ & $8.10 \pm 1.28$ & NS & $0.664^{* *}$ & $8.39 \pm 2.34$ & $9.15 \pm 1.89$ & NS & 0.372 \\
\hline Zn (mg) & $9.45 \pm 2.16$ & $10.0 \pm 1.85$ & NS & $0.620^{* *}$ & $8.70 \pm 1.46$ & $10.4 \pm 2.57$ & NS & 0.595 \\
\hline $\mathrm{Cu}(\mathrm{mg})$ & $1.22 \pm 0.243$ & $1.44 \pm 0.298$ & $*$ & 0.322 & $1.20 \pm 0.234$ & $1.33 \pm 0.216$ & NS & 0.318 \\
\hline Mn (mg) & $2.88 \pm 0.566$ & $3.35 \pm 0.932$ & NS & $0.583^{*}$ & $2.84 \pm 0.553$ & $3.73 \pm 0.743$ & $* *$ & 0.505 \\
\hline V.A $(\mu \mathrm{g})$ & $1049 \pm 358$ & $1,006 \pm 452$ & NS & 0.368 & $1,153 \pm 362$ & $970 \pm 329$ & NS & -0.231 \\
\hline V.D $(\mu \mathrm{g})$ & $6.12 \pm 4.02$ & $7.30 \pm 3.46$ & NS & $0.644^{* *}$ & $7.62 \pm 3.98$ & $9.78 \pm 3.38$ & NS & 0.417 \\
\hline V.E (mg) & $7.71 \pm 1.74$ & $8.32 \pm 1.53$ & NS & 0.432 & $14.3 \pm 18.4$ & $8.79 \pm 1.30$ & NS & -0.374 \\
\hline V.K $(\mu \mathrm{g})$ & $304 \pm 128$ & $247 \pm 87.1$ & NS & 0.433 & $383 \pm 209$ & $313 \pm 153$ & NS & $0.671^{*}$ \\
\hline V.B $(\mathrm{mg})$ & $0.855 \pm 0.188$ & $1.09 \pm 0.256$ & $* *$ & $0.568^{*}$ & $0.791 \pm 0.212$ & $0.985 \pm 0.225$ & NS & 0.254 \\
\hline V.B $\mathrm{B}_{2}(\mathrm{mg})$ & $1.12 \pm 0.235$ & $1.36 \pm 0.299$ & $*$ & $0.823^{* * *}$ & $1.07 \pm 0.150$ & $1.33 \pm 0.257$ & $*$ & 0.614 \\
\hline Niacin (mg) & $15.4 \pm 4.54$ & $19.4 \pm 5.64$ & $*$ & $0.731^{* * *}$ & $13.4 \pm 2.98$ & $18.2 \pm 3.45$ & $* *$ & -0.010 \\
\hline $\mathrm{V}^{\mathrm{B}} \mathrm{B}_{6}(\mathrm{mg})$ & $1.25 \pm 0.286$ & $1.39 \pm 0.288$ & NS & $0.740^{* * *}$ & $1.23 \pm 0.288$ & $1.55 \pm 0.446$ & NS & 0.286 \\
\hline $\mathrm{V} \mathrm{B}_{12}(\mu \mathrm{g})$ & $7.79 \pm 3.70$ & $8.44 \pm 4.17$ & NS & $0.685^{* *}$ & $6.99 \pm 3.57$ & $10.4 \pm 6.79$ & NS & $0.863^{* *}$ \\
\hline $\mathrm{Fa}(\mu \mathrm{g})$ & $361 \pm 74.8$ & $350 \pm 58.0$ & NS & $0.549^{*}$ & $355 \pm 77.6$ & $328 \pm 71.1$ & NS & $0.678^{*}$ \\
\hline $\mathrm{Pa}(\mathrm{mg})$ & $5.70 \pm 1.28$ & $6.42 \pm 1.22$ & NS & $0.822^{* * *}$ & $5.58 \pm 0.728$ & $6.46 \pm 1.39$ & NS & $0.634^{*}$ \\
\hline V.C (mg) & $101 \pm 25.7$ & $116 \pm 59.8$ & NS & $0.775^{* * *}$ & $98.5 \pm 24.5$ & $96.6 \pm 36.8$ & NS & $0.647^{*}$ \\
\hline Cho (mg) & $314 \pm 103$ & $370 \pm 145$ & NS & $0.907^{* * *}$ & $378 \pm 119$ & $429 \pm 135$ & NS & $0.702^{*}$ \\
\hline $\mathrm{Df}(\mathrm{g})$ & $13.6 \pm 2.85$ & $13.8 \pm 2.66$ & NS & $0.807^{* * *}$ & $13.6 \pm 2.99$ & $13.3 \pm 1.79$ & NS & 0.558 \\
\hline Salt (g) & $9.64 \pm 1.89$ & $8.87 \pm 1.95$ & NS & 0.240 & $9.99 \pm 1.88$ & $10.4 \pm 2.97$ & NS & 0.609 \\
\hline
\end{tabular}

Each value is mean \pm SD.

E: energy, P: protein, F: fat, C: carbohydrate, Fa: folacin, Pa: pantothenic acid, Cho: cholesterol, Df: dietary fiber.

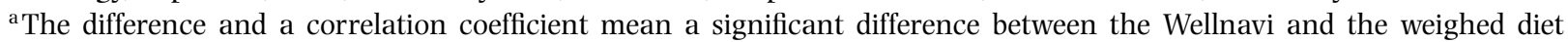
record methods.

${ }^{* * *} p<0.001,{ }^{* *} p<0.01,{ }^{*} p<0.05$.

daily nutrient intakes estimated by the Wellnavi method and the weighed diet record method were obtained in all the subjects (Table 2), and in the male subjects and female subjects (Table 3). The correlation coefficients between the dietary nutrient intakes estimated by these two dietary assessment methods ranged from 0.340 for folacin to 0.776 for vitamin $\mathrm{D}$ in all the subjects (Table 2 ), from 0.408 for salt to 0.833 for cholesterol in male subjects and from 0.310 for magnesium to 0.802 for vitamin D in female subjects (Table 3). However, the estimated the daily nutrient intakes by the Wellnavi method were significantly lower in all subjects, male subjects and female subjects than those obtained from the weighed diet record method. The Wellnavi method is an instrument to send electronically the nutrient intakes calculated based on a digital photo of their meal by the dietician to them. In order to accurately estimate for the portion size of the consumed foods in the digital photo, it is necessary that the digital photo of the meal be taken by the Wellnavi instrument held at an angle of 45 degrees to the meal (14). In this study, most of the subjects were not taking the photo of their meal at an angle of 45 degrees. This fact was regarded as one of the reasons that the dietician could not accurately judge the amounts of the consumed foods. The Wellnavi instrument has a function to help dieticians understand what food the subject has consumed by the subject's writing down with a stylus the food names on the display. Moreover, because many subjects in this study did not use this function, from the electronically transmitted digital photo alone, the dietitian could not estimate the food name or the amount of foods such as omelets, hamburger steaks, fries, curry and rice, croquettes and stew. Traditional Japanese foods such as miso soup, miso soup with pork and vegetables, rice cakes boiled with vegetables, rice and vegetable porridge and onepot meals were often eaten by the subjects, because the diet survey was carried out in the winter. Because some 
Table 5. The difference and the correlation coefficient in estimated daily nutrient intake in nonobese and obese women between the two dietary assessment methods.

\begin{tabular}{|c|c|c|c|c|c|c|c|c|}
\hline & \multicolumn{4}{|c|}{ Nonobese women $(n=26)$} & \multicolumn{4}{|c|}{ Obese women $(n=22)$} \\
\hline & $\begin{array}{l}\text { Wellnavi } \\
\mathrm{M} \pm \mathrm{SD}\end{array}$ & $\begin{array}{l}\text { Weighed diet } \\
\text { record } \\
\mathrm{M} \pm \mathrm{SD}\end{array}$ & Difference $^{\mathrm{a}}$ & $\begin{array}{l}\text { Correlation } \\
\text { coefficient }^{\mathrm{a}}\end{array}$ & $\begin{array}{l}\text { Wellnavi } \\
\mathrm{M} \pm \mathrm{SD}\end{array}$ & $\begin{array}{l}\text { Weighed diet } \\
\text { record } \\
\mathrm{M} \pm \mathrm{SD}\end{array}$ & Difference $^{\mathrm{a}}$ & $\begin{array}{l}\text { Correlation } \\
\text { coefficient }^{\mathrm{a}}\end{array}$ \\
\hline E (kcal) & $1,664 \pm 392$ & $1,900 \pm 264$ & * & 0.338 & $1,593 \pm 294$ & $1,755 \pm 360$ & NS & $0.708^{* * *}$ \\
\hline $\mathrm{P}(\mathrm{g})$ & $67.5 \pm 17.4$ & $78.1 \pm 16.2$ & $*$ & $0.515^{* *}$ & $63.3 \pm 12.1$ & $73.0 \pm 18.1$ & $*$ & $0.528^{*}$ \\
\hline $\mathrm{F}(\mathrm{g})$ & $48.2 \pm 13.8$ & $53.7 \pm 15.8$ & NS & $0.616^{* * *}$ & $42.6 \pm 11.7$ & $44.3 \pm 11.7$ & NS & $0.549^{* *}$ \\
\hline $\mathrm{C}(\mathrm{g})$ & $230 \pm 57.6$ & $269 \pm 41.7$ & $* *$ & 0.198 & $231 \pm 45.5$ & $257 \pm 58.8$ & NS & $0.735^{* * *}$ \\
\hline $\mathrm{Na}(\mathrm{mg})$ & $3,691 \pm 802$ & $3,643 \pm 853$ & NS & -0.026 & $3,627 \pm 950$ & $3,353 \pm 998$ & NS & $0.532 *$ \\
\hline $\mathrm{K}(\mathrm{mg})$ & $2,383 \pm 609$ & $3,335 \pm 926$ & $* * *$ & 0.234 & $2,404 \pm 564$ & $3,198 \pm 1,326$ & $*$ & $0.554^{* *}$ \\
\hline $\mathrm{Ca}(\mathrm{mg})$ & $470 \pm 150$ & $611 \pm 175$ & $* *$ & 0.355 & $447 \pm 130$ & $546 \pm 161$ & $*$ & 0.145 \\
\hline $\operatorname{Mg}(\mathrm{mg})$ & $242 \pm 51.1$ & $324 \pm 80.1$ & $* * *$ & 0.094 & $250 \pm 62.7$ & $312 \pm 92.4$ & $*$ & $0.505^{*}$ \\
\hline $\mathrm{P}(\mathrm{mg})$ & $962 \pm 242$ & $1176 \pm 220$ & $* *$ & $0.460^{*}$ & $916 \pm 181$ & $1,081 \pm 275$ & $*$ & $0.472^{*}$ \\
\hline $\mathrm{Fe}(\mathrm{mg})$ & $7.98 \pm 1.93$ & $9.40 \pm 2.12$ & $*$ & 0.069 & $9.30 \pm 6.81$ & $9.87 \pm 3.34$ & NS & -0.011 \\
\hline Zn (mg) & $8.28 \pm 2.06$ & $9.47 \pm 1.91$ & $*$ & $0.410^{*}$ & $7.93 \pm 2.08$ & $9.28 \pm 2.50$ & NS & $0.729^{* * *}$ \\
\hline $\mathrm{Cu}(\mathrm{mg})$ & $1.14 \pm 0.408$ & $1.51 \pm 0.699$ & $*$ & $0.700^{* * *}$ & $1.15 \pm 0.300$ & $1.38 \pm 0.425$ & $*$ & $0.584^{* *}$ \\
\hline Mn (mg) & $2.66 \pm 0.618$ & $6.75 \pm 7.15$ & $* *$ & -0.012 & $2.86 \pm 0.631$ & $8.83 \pm 10.9$ & $*$ & $0.464^{*}$ \\
\hline V.A $(\mu \mathrm{g})$ & $967 \pm 401$ & $1,167 \pm 317$ & NS & 0.222 & $1,066 \pm 403$ & $1,140 \pm 600$ & NS & $0.753^{* * *}$ \\
\hline V.D $(\mu \mathrm{g})$ & $9.51 \pm 7.09$ & $10.2 \pm 6.12$ & NS & $0.772^{* * *}$ & $8.66 \pm 5.67$ & $10.7 \pm 7.49$ & NS & $0.889^{* * *}$ \\
\hline V.E (mg) & $7.48 \pm 2.42$ & $8.52 \pm 1.75$ & NS & $0.552^{* *}$ & $7.98 \pm 2.47$ & $8.39 \pm 2.78$ & NS & $0.584^{* *}$ \\
\hline V.K $(\mu \mathrm{g})$ & $276 \pm 155$ & $318 \pm 162$ & NS & $0.532^{* *}$ & $328 \pm 171$ & $381 \pm 290$ & NS & 0.346 \\
\hline V.B $B_{1}(\mathrm{mg})$ & $0.795 \pm 0.211$ & $1.03 \pm 0.218$ & $* * *$ & $0.430^{*}$ & $0.732 \pm 0.177$ & $0.933 \pm 0.244$ & $* *$ & $0.439^{*}$ \\
\hline V.B $\mathrm{B}_{2}(\mathrm{mg})$ & $1.05 \pm 0.348$ & $1.47 \pm 0.335$ & $* * *$ & $0.535^{* *}$ & $1.04 \pm 0.213$ & $1.36 \pm 0.435$ & $* *$ & $0.544^{* *}$ \\
\hline Niacin (mg) & $13.9 \pm 3.73$ & $19.3 \pm 6.60$ & $* * *$ & 0.136 & $13.6 \pm 3.89$ & $18.1 \pm 6.03$ & $* *$ & $0.743^{* * *}$ \\
\hline $\mathrm{V} \mathrm{B}_{6}(\mathrm{mg})$ & $1.15 \pm 0.297$ & $1.42 \pm 0.263$ & $* *$ & $0.610^{* * *}$ & $1.14 \pm 0.283$ & $1.44 \pm 0.504$ & $*$ & $0.680^{* * *}$ \\
\hline V.B $\mathrm{B}_{12}(\mu \mathrm{g})$ & $8.41 \pm 5.62$ & $9.19 \pm 5.25$ & NS & $0.789^{* * *}$ & $8.61 \pm 5.20$ & $9.91 \pm 8.20$ & NS & $0.846^{* * *}$ \\
\hline $\mathrm{Fa}(\mu \mathrm{g})$ & $325 \pm 86.7$ & $527 \pm 245$ & $* * *$ & 0.049 & $366 \pm 97.9$ & $574 \pm 407$ & $*$ & $0.577^{* *}$ \\
\hline $\mathrm{Pa}(\mathrm{mg})$ & $5.43 \pm 1.55$ & $6.69 \pm 1.21$ & $* *$ & $0.625^{* * *}$ & $5.16 \pm 1.10$ & $6.26 \pm 1.55$ & $*$ & $0.574^{* *}$ \\
\hline V.C (mg) & $95.3 \pm 39.6$ & $150 \pm 61.0$ & $* * *$ & 0.311 & $100 \pm 26.4$ & $143 \pm 74.4$ & $*$ & $0.670^{* * *}$ \\
\hline Cho (mg) & $353 \pm 168$ & $400 \pm 149$ & NS & $0.752^{* * *}$ & $304 \pm 104$ & $326 \pm 167$ & NS & $0.729^{* * *}$ \\
\hline Df $(\mathrm{g})$ & $13.2 \pm 3.24$ & $18.4 \pm 7.38$ & $* *$ & $0.413^{*}$ & $13.8 \pm 3.57$ & $16.6 \pm 6.55$ & NS & 0.300 \\
\hline Salt (g) & $9.32 \pm 2.04$ & $9.21 \pm 2.16$ & NS & -0.030 & $9.15 \pm 2.39$ & $8.46 \pm 2.51$ & NS & $0.528^{*}$ \\
\hline
\end{tabular}

Each value is mean \pm SD.

E: energy, P: protein, F: fat, C: carbohydrate, Fa: folacin, Pa: pantothenic acid, Cho: cholesterol, Df: dietary fiber.

${ }^{a}$ The difference and a correlation coefficient mean a significant difference between the Wellnavi and the weighed diet record methods.

${ }^{* * *} p<0.001,{ }^{* *} p<0.01,{ }^{*} p<0.05$.

Table 6. Comparison of the daily energy intake from the weighed diet record method with daily energy expenditure from the motion and time study in the nonobese and obese men, and the nonobese and obese women.

\begin{tabular}{llcc}
\hline \multirow{2}{*}{ Wen } & Nonobese & $\begin{array}{c}\text { Weighed diet } \\
\text { record mehod } \\
(\mathrm{kcal} / \mathrm{d})\end{array}$ & $\begin{array}{c}\text { Motion and } \\
\text { time study } \\
(\mathrm{kcal} / \mathrm{d})\end{array}$ \\
\hline \multirow{2}{*}{ Women } & Obese & $2,256 \pm 355$ & $2,318 \pm 374$ \\
& Nonobese & $1,906 \pm 280$ & $1,813 \pm 174$ \\
& Obese & $1,898 \pm 204$ & $2,070 \pm 204$ \\
\hline
\end{tabular}

Each value is mean \pm SD.

ingredients in these dishes are not observable, it is not possible to visually identify the ingredients constituting these dishes. The nutrient intakes from these dishes can't be calculated for dietary assessment.

In order to estimate more accurately the portion size of the consumed foods, this instrument should have a touch-screen function list of popular food items with various portion sizes from which the subject can choose. Since the quality of the digital photo from the Wellnavi instrument was not good, it is difficult to discriminate between burdock and meat, cheese and pickled radish, and seaweed and green vegetables. The quality of the digital photo by the Wellnavi instrument should be improved in order to facilitate the discrimination of the foods in the dishes.

On the other hand, it is known that the underreporting of energy intake has been observed in obese people (7-12), women $(4,10,12,23)$, older men and women (24) and relatively lean Japanese females (25). However, in this study, obesity in women was not a factor in the underreporting of dietary intake estimated with the Wellnavi instrument, but the presence of this relation 
was undeniable in the obese men (Tables 4 and 5). Some investigators have reported that with the help of the digital photography estimation method they can directly observe food intake and plate waste, and can avoid small overestimates and underestimates (26-28).

The Wellnavi method is a kind of digital photography estimation method. To write down the food name on the screen of this instrument can be the part of the function of the diet record method. In short, these two functions of this instrument may be preventing measurement errors in dietary intake.

At present, the mobile phone with photograph function is popularly used in the society and many people over a wide range of age use this function daily. In short, the Wellnavi instrument is the same kind of system as the mobile phone. The Wellnavi method is suitable for a long-term dietary survey, because the burden to the participants is not significantly heavy. Therefore, it can be expected that this method will make exciting progress as a new dietary assessment method for the IT age.

\section{Acknowledgments}

We wish to thank Junko Hashimoto and Fumio Seno for data collection. This study was funded by Health Sciences Research Grants on Health Services from the Ministry of Health, Labour and Welfare, Japan.

\section{REFERENCES}

1) Willett W. 1998. Overview of nutritional epidemiology. In: Nutritional Epidemiology (Willett W, ed), p 3-17. Oxford University Press, New York.

2) Buzzard M. 1998. 24-hour dietary recall and food record methods. In: Nutritional Epidemiology (Willett W, ed), p 50-100. Oxford University Press, New York.

3) Frances ET, Tim B. 1994. Dietary assessment resource manual. J Nutr 124: 2245S-2317S.

4) Novotny JA, Rumpler WV, Riddick H, Hebert JR, Rhodes D, Judd JT, Baer DJ, Mcdowell M, Briefel R. 2003. Personality characteristics as predictors of underreporting of energy intake on 24-hour dietary recall interviews. J Am Diet Assoc 103: 1146-1151.

5) Sawaya AL, Tucker K, Tsay R, Willet W, Saltzman E, Dallal GE, Roberts SB. 1996. Evaluation of four methods for determining energy intake in young and older women: comparison with doubly labeled water measurements of total energy expenditure. Am J Clin Nutr 63: 491-499.

6) Hill RJ, Davies PSW. 2001. The validity of self-reported energy intake as determined using the doubly labelled water technique. Br J Nutr 85: 415-430.

7) Lavienja AJL, Braam MC, Ocke H, Bas BdM, Jaap CS. 1998. Determinants of obesity-related underreporting of energy intake. Am J Epidemiol 147: 1081-1086.

8) Bandini LG, Schoeller DA, Cyr HN, Dietz WH. 1990. Validity of reported energy intake in obese and nonobese adolescents. Am J Clin Nutr 52: 421-425.

9) Lichtman SW, Pisarska K, Baynes BE. 1992. Discrepancy between self-reported and actual caloric intake and exercise in obese subjects. N Engl J Med 27: 18931898.

10) Prentice AM, Black AE, Coward WA. 1986. High levels of energy expenditure in obese women. Br Med J 292: 983-987.
11) Vries JHM, Zock PL, Mensink RP, Katan MB. 1994. Underestimation of energy intake by 3 -d records compared with energy intake to maintain body weight in 269 nonobese adults. Am J Clin Nutr 60: 855-860.

12) Johansson L, Solvoll K, Bjorneboe GEA, Drevon CA. 1998. Under- and overreporting of energy intake related to weight status and lifestyle in a nationwide sample. Am J Clin Nutr 68: 266-274.

13) Mertz W. 1992. Food intake measurements: is there a "gold standard"? J Am Diet Assoc 92: 1463-1465.

14) Wang DH, Kogashiwa M, Ohta S, Kira S. 2002. Validity and reliability of a dietary assessment method: The application of a digital camera with a mobile phone card attachment. J Nutr Sci Vitaminol 48: 498-504.

15) Science and Technology Agency. 2000. Standard Tables of Food Composition in Japan, 5th Revision. Printing Bureau, Ministry of Finance, Tokyo (in Japanese).

16) Matsuzawa Y, Inoue S, Ikeda Y, Sakata T, Saito Y, Sato Y, Sirai A, Ohono M, Miyazaki S, Tokunaga T, Fukagawa K, Yamanouti K, Nakamura T. 2000. The judgment criteria for new overweight, and the diagnostic standard for obesity. Obes Res 6: 18-28 (in Japanese).

17) Scholler DA. 1990. How accurate is self-reported dietary energy intake? Nutr Rev 48: 373-379.

18) Scholler DA. 1988. Measurement of energy expenditure in free-living human beings by using doubly labeled water. J Nutr 118: 1278-1289.

19) Supervised by Health Promotion and Nutrition Division, Health Service Bureau, Ministry of Health and Welfare (ed). 1994. Recommended Dietary Allowances for the Japanese, 5th Revision. Dai-ichi Shuppan, Tokyo (in Japanese).

20) Elizabeth BC. 1991. Nutrition epidemiology: how do we know what they ate? Am J Clin Nutr 54: 182S-187S.

21) Black AE, Cole TJ. 2001. Biased over- or under-reporting is characteristic of individuals whether over time or by different assessment method. J Am Diet Assoc 101: 70-80.

22) Livingstone MBE, Black AE. 2003. Markers of the validity of reported energy intake. J Nutr 133: 895S-920S.

23) Briefel RR, McDowell MA, Alaimo K, Caughman CR, Bischof AL, Carroll MD, Johnson CL. 1995. Total energy intake of the US population: the third National and Nutrition Examination Survey, 1988-1991. Am J Clin Nutr 62 (Suppl): 1072S-1080S.

24) Johnson RK, Goran MI, Poehlman ET. 1994. Correlates of over- and underreporting of energy intake in healthy older men and women. Am J Clin Nutr 59: 1286-1290.

25) Okubo H, Sasaki S. 2004. Underreporting of energy intake among Japanese women aged 18-20 years and its association with reported nutrient and food group intakes. Public Health Nutr 7: 911-917.

26) Nelson M, Atkinson M, Darbyshire S. 1994. Food photography I: the perception of food portion size from photographs. Br J Nutr 72: 649-663.

27) Suzuki A, Miyauchi M, Hattori I, Egami I, Wakai K, Tamakoshi A, Ando M, Nakayama T, Ohno Y, Kawamura T. 2002. Inter-observer agreement and validity of photographic dietary assessment. Jpn Public Health 49: 749-758 (in Japanese).

28) Williamson DA, Allen HR, Martin PD, Alfonso AJ, Gerald B, Hunt A. 2003. Comparison of digital photography to weighed and visual estimation of portion sizes. $J$ Am Diet Assoc 103: 1139-1145. 